\title{
A Comprehensive Quantitative Genetic Analysis of Cerebral Surface Area in Youth
}

\author{
๑) J. Eric Schmitt, ${ }^{1}{ }^{\oplus}$ Michael C. Neale, ${ }^{2}$ Liv S. Clasen, ${ }^{3}$ Siyuan Liu, ${ }^{3}$ Jakob Seidlitz, ${ }^{3}{ }^{-}$Joshua N. Pritikin, ${ }^{2}{ }^{\circledR}$ Alan Chu, ${ }^{4}$ \\ (D) Gregory L. Wallace, ${ }^{5}$ Nancy Raitano Lee, ${ }^{6}$ Day N. Giedd, ${ }^{7}$ and ${ }^{\text {DDAmin Raznahan }}{ }^{3}$ \\ ${ }^{1}$ Departments of Radiology and Psychiatry, Division of Neuroradiology, Brain Behavior Laboratory, Hospital of the University of Pennsylvania, \\ Philadelphia, Pennsylvania 19104, ${ }^{2}$ Departments of Psychiatry and Genetics, Virginia Institute for Psychiatric and Behavioral Genetics, Virginia \\ Commonwealth University, Richmond, Virginia 23298, ${ }^{3}$ Developmental Neurogenomics Unit, Human Genetics Branch, National Institute of Mental Health, \\ Bethesda, Maryland 20892, ${ }^{4}$ Department of Radiology, Hospital of the University of Pennsylvania, Philadelphia, Pennsylvania 19104, ${ }^{5}$ Department of \\ Speech, Language, and Hearing Sciences, George Washington University, Washington, DC 20052, ${ }^{\circ}$ Department of Psychology, Drexel University, \\ Philadelphia, Pennsylvania 19104, and 7Department of Psychiatry, University of California at San Diego, La Jolla, California 92093
}

The genetics of cortical arealization in youth is not well understood. In this study, we use a genetically informative sample of 677 typically developing children and adolescents (mean age 12.72 years), high-resolution MRI, and quantitative genetic methodology to address several fundamental questions on the genetics of cerebral surface area. We estimate that $>85 \%$ of the phenotypic variance in total brain surface area in youth is attributable to additive genetic factors. We also observed pronounced regional variability in the genetic influences on surface area, with the most heritable areas seen in primary visual and visual association cortex. A shared global genetic factor strongly influenced large areas of the frontal and temporal cortex, mirroring regions that are the most evolutionarily novel in humans relative to other primates. In contrast to studies on older populations, we observed statistically significant genetic correlations between measures of surface area and cortical thickness $\left(r_{\mathrm{G}}=0.63\right)$, suggestive of overlapping genetic influences between these endophenotypes early in life. Finally, we identified strong and highly asymmetric genetically mediated associations between Full-Scale Intelligence Quotient and left perisylvian surface area, particularly receptive language centers. Our findings suggest that spatially complex and temporally dynamic genetic factors are influencing cerebral surface area in our species.

Key words: cortical thickness; genetics; intelligence; MRI; neurodevelopment; surface area

Significance Statement

Over evolution, the human cortex has undergone massive expansion. In humans, patterns of neurodevelopmental expansion mirror evolutionary changes. However, there is a sparsity of information on how genetics impacts surface area maturation. Here, we present a systematic analysis of the genetics of cerebral surface area in youth. We confirm prior research that implicates genetics as the dominant force influencing individual differences in global surface area. We also find evidence that evolutionarily novel brain regions share common genetics, that overlapping genetic factors influence both area and thickness in youth, and the presence of strong genetically mediated associations between intelligence and surface area in language centers. These findings further elucidate the complex role that genetics plays in brain development and function.

\section{Introduction}

Evolutionary advances in higher cognitive functions have been accompanied by dramatic increases in both the size and complex-

\footnotetext{
Received Aug. 29, 2018; revised Jan. 21, 2019; accepted Jan. 29, 2019.

Author contributions: J.E.S., M.C.N., J.N.G., and A.R. designed research; J.E.S., L.S.C., G.L.W., N.R.L., J.N.G., and A.R. performed research;J.E.S., S.L., J.S., A.C., and J.N.G. analyzed data; J.E.S. wrote the first draft of the paper; J.E.S., M.C.N., L.S.C., S.L., J.S., J.N.P., A.C., G.L.W., N.R.L., J.N.G., and A.R. edited the paper; J.N.P. contributed unpublished reagents/analytic tools.

This work was supported by National Institute of Mental Health Grant MH-20030 and Big Data to Knowledge Grant K01-ES026840 through the National Cancer Institute.

The authors declare no competing financial interests.
}

ity of the human telencephalon (Carroll, 2003). The expansion of the cortical sheet in Homo sapiens has been nearly entirely driven by increases in cerebral surface area (SA). For example, human cortical SA is on average 1000 times larger than that of mice, whereas cortical thickness (CT) is only doubled (Rakic, 2009). Interestingly, the regions of the greatest evolutionary expansion in SA tend to mirror those with the greatest change during human

Correspondence should be addressed to J. Eric Schmitt at eric.schmitt@stanfordalumni.org. https://doi.org/10.1523/JNEUROSCI.2248-18.2019

Copyright $\odot 2019$ the authors 
Table 1. Demographic characteristics of the sample

\begin{tabular}{llllll}
\hline & MZ & DZ & Siblings of twins & Singletons & Total \\
\hline Sample size & 222 & 101 & 84 & 270 & 677 \\
Mean \pm SD & $12.55(3.30)$ & $12.24(3.29)$ & $12.98(3.96)$ & $12.95(4.62)$ & $12.72(3.95)$ \\
age (years) & & & & & \\
Gender & $103 \mathrm{~F}$ & $46 \mathrm{~F}$ & $48 \mathrm{~F}$ & $126 \mathrm{~F}$ & $323 \mathrm{~F}$ \\
& $119 \mathrm{M}$ & $55 \mathrm{M}$ & $36 \mathrm{M}$ & $144 \mathrm{M}$ & $354 \mathrm{M}$ \\
Handedness & $193 \mathrm{R}$ & $83 \mathrm{R}$ & $67 \mathrm{R}$ & $241 \mathrm{R}$ & $584 \mathrm{R}$ \\
& $15 \mathrm{M}$ & $10 \mathrm{M}$ & $7 \mathrm{M}$ & $18 \mathrm{M}$ & $50 \mathrm{M}$ \\
& $13 \mathrm{~L}$ & $8 \mathrm{~L}$ & $9 \mathrm{~L}$ & $11 \mathrm{~L}$ & $41 \mathrm{~L}$ \\
FSIQ & $110.45(11.68)$ & $111.71(11.88)$ & $113.93(12.55)$ & $115.95(12.06)$ & $113.22(12.19)$ \\
\hline
\end{tabular}

neurodevelopment (Hill et al., 2010). More rapidly expanding regions also show the strongest correlations with intellectual ability (Fjell et al., 2015). Thus, there has been increasing interest in what common genetic factors influence both evolutionary and neurodevelopmental processes in humans (Reardon et al., 2018).

There are profound within-species individual differences in human brain structure. For example, the size of the human cerebral cortex can vary by nearly a factor of 2 in similarly aged youth (Giedd et al., 2015). Understanding the nature of these observed individual differences in brain structure remains an area of active investigation. Prior in vivo studies in children and adolescents using MRI have shown that both cerebral volumes and CT are highly heritable (Wallace et al., 2006; Schmitt et al., 2007; Lenroot et al., 2009). Studies in older adults have demonstrated very high and relatively uniform heritabilities in SA throughout the cerebrum (Panizzon et al., 2009; Eyler et al., 2011, 2012). SA also appears genetically orthogonal to CT in older samples (Panizzon et al., 2009).

However, the literature on the genetics of cortical arealization area is limited in children and adolescents, with the few prior studies presenting conflicting results. This is particularly problematic given that cerebral SA changes most rapidly during childhood (Schnack et al., 2015), and the dominant theories on its genetics are based on early neurodevelopmental processes whose effects may be attenuated later in life (Rubenstein and Rakic, 1999; Rakic, 2009). In the current study, we describe results from a systematic examination of cortical arealization in a large genetically informative pediatric neuroimaging sample.

\section{Materials and Methods}

Subjects. A total of 677 typically developing children, adolescents, and young adults (mean age 12.72 years) from 382 families were recruited by the Child Psychiatry Branch of the National Institute of Mental Health. The sample included pediatric, adolescent, and young adult monozygotic twins ( $M Z, N=222$ ), dizygotic twins ( $D Z, N=101)$, siblings of twins $(N=84)$, and singleton $(N=270)$ nontwin family members (Table 1). Details of this sample have been described previously (Lenroot et al., 2009). Parents of prospective participants were interviewed by phone and asked to report their child's developmental, educational, and health history. Subjects were excluded if they had been diagnosed with a psychiatric disorder, taken psychiatric medications, had experienced brain trauma, or had any condition known to affect gross brain development. Inclusion criteria were a minimum gestational age of 29 weeks and a minimum birth weight of $1500 \mathrm{~g}$. Approximately $80 \%$ of families responding to the ads met inclusion criteria.

For twin subjects, zygosity was determined by DNA analysis of buccal cheek swabs (BRT Laboratories and Proactive Genetics) using 9-21 unlinked short tandem repeat loci for a minimum certainty of $99 \%$. We obtained verbal or written assent from the child and written consent from the parents for their participation in the study. The Combined Neurosciences Institutional Review Board at the National Institutes of Health approved the protocol.

For each subject, age-appropriate versions of a Wechsler Intelligence scale were administered. Full-Scale IQ (FSIQ) data were available for 663
(98\%) of the participants; 597 subjects (90\%) were administered the Wechsler Abbreviated Scale of Intelligence, 47 (7\%) were administered the Wechsler Intelligence Scale for Children-Revised, and the remaining $3 \%$ of subjects were administered either versions of the Wechsler Preschool and Primary Scale of Intelligence or the Wechsler Adult Intelligence Scale.

MRI acquisition. All MRI images were acquired on the same 1.5 Tesla Signa Scanner (General Electric) located at the National Institutes of Health Clinical Center (Bethesda, Maryland). A 3D spoiled gradientrecalled echo sequence in the steady-state sequence was used to acquire 124 contiguous $1.5-\mathrm{mm}$-thick slices in the axial plane $(\mathrm{TE} / \mathrm{TR}=5 / 24 \mathrm{~ms}$; flip angle $=45$ degrees, matrix $=256 \times 192, \mathrm{NEX}=1, \mathrm{FOV}=24 \mathrm{~cm}$, acquisition time $9.9 \mathrm{~min})$. A Fast Spin Echo/Proton Density weighted imaging sequence was also acquired for clinical evaluation.

Image analysis. All MR images were imported into the CIVET pipeline for automated structural image processing (Ad-Dab'bagh et al., 2006). Briefly, the native MRI scans were registered into standardized stereotaxic space using a linear transformation (Collins et al., 1994) and corrected for nonuniformity (Sled et al., 1998). The registered and corrected volumes were segmented into white matter, gray matter, CSF, and background using a neural net classifier (Zijdenbos et al., 2002). The gray and white matter surfaces were fitted using deformable surface-mesh models and nonlinearly aligned toward a template surface (MacDonald et al., 2000; Robbins et al., 2004; Kim et al., 2005). The gray and white matter surfaces were resampled into native space. At each of $\sim 80,000$ vertices, SA was calculated at the geometric center between inner and outer cortical surfaces (Lyttelton et al., 2009). CT was measured in native space using the linked distance between the white and pial surfaces (MacDonald et al., 2000; Lerch and Evans, 2005).

Experimental design and statistical analysis. Each subject's neuroanatomic measures were imported into the $\mathrm{R}$ statistical environment for analysis (R Core Team, 2018). The data were reformatted such that each record represented family-wise (rather than individual-wise) data. Genetic modeling was performed in OpenMx, a structural equation modeling package fully integrated into the R environment (Boker et al., 2011; Neale et al., 2016). First, global and vertex-level univariate analyses of SA were performed via the classic ACE model with an extended twin design (Posthuma and Boomsma, 2000). This model decomposes the observed phenotypic variance into components attributable to additive genetic (A), shared environmental (C), and unique environmental factors (E), including measurement error (Neale and Cardon, 1992; Lenroot et al., 2009). Mathematically, these variance components can be estimated based on the observed phenotypic variance and cross-twin or crosssibling covariances. For example:

$$
\begin{aligned}
& V_{P}=A+C+E \\
& \operatorname{Cov}_{M Z}=A+C \\
& \operatorname{Cov}_{D Z}=\frac{1}{2} A+C
\end{aligned}
$$

Where $V_{P}$ represents the observed phenotypic variance, $\operatorname{Cov}_{M Z}$ the monozygotic twin-twin phenotypic covariance, and $\operatorname{Cov}_{D Z}$ the dizygotic phenotypic covariance. From these three linear equations, the variance attributable to additive genetic factors (A) can be estimated, as well as estimates for the shared $(\mathrm{C})$ and unique (E) environmental variance. Proportional variance estimates (e.g., the heritability, $\mathrm{A} / V_{P}$, or $\mathrm{a}^{2}$ ) can subsequently be calculated.

The model also contained parameters to adjust for sex and linear and nonlinear effects of age on the mean. Optimum model fit was determined using maximum likelihood (Edwards, 1972). To test for statistical significance, fit was compared with submodels with either genetic or shared environmental parameters removed (CE and AE models, respectively); differences in model fit asymptotically follow a 50:50 mixture of 0 and $\chi^{2}$ with $1 \mathrm{df}$ (Dominicus et al., 2006). Familial variance (combined additive genetic and shared environmental variance) was also assessed by comparing the ACE model to a submodel in which both familial factors were simultaneously removed. Control for multiple testing was performed with the false discovery rate (FDR) (Genovese et al., 2002). To investigate 


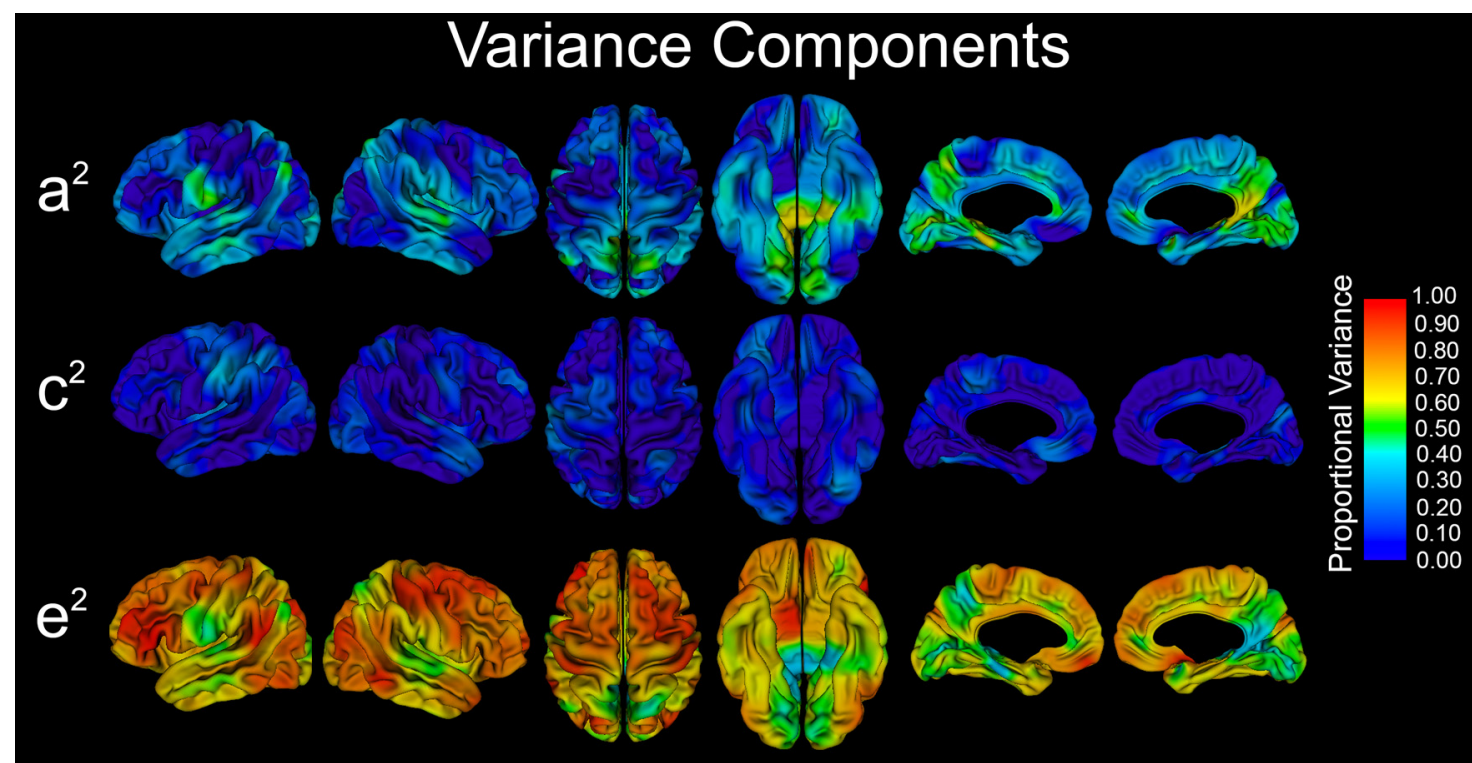

Hypothesis Tests

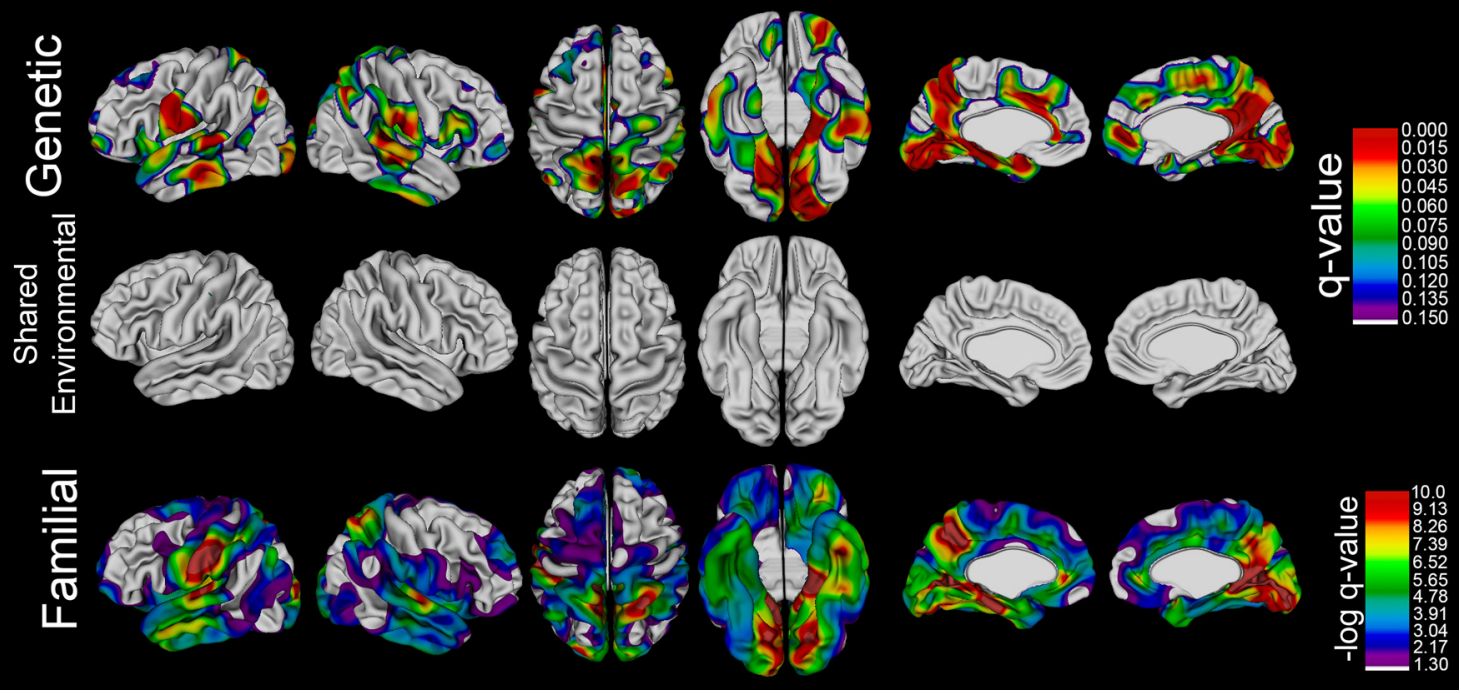

Figure 1. The heritability of cerebral $S A$ in children and adolescents. Maximum likelihood estimates for additive genetic $\left(\mathrm{a}^{2}\right)$, shared environmental $\left(\mathrm{C}^{2}\right)$, and unique environmental $\left(\mathrm{e}^{2}\right)$ variance in vertex-level cerebral SA are shown for multiple views. Probability maps identifying regions with statistically significant variation are also shown. Gray represents nonsignificant vertices. There were no statistically significant shared environmental effects after correction for multiple testing. Probability maps for familial $\left(\mathrm{a}^{2}+\mathrm{c}^{2}\right)$ covariance also are provided. Because the power to identify familial effects is greater than for individual variance components, a logarithmic scale is use to better visualize regional differences.

potential global effects on vertex-level measures, we repeated these analyses, including standardized total cerebral SA as an additional covariate. Given the negligible role of the shared environment in these univariate models, it was removed from subsequent analyses.

We hypothesized that a global genetic factor influenced regional genetic variance. As a second perspective on the influence of global measures on vertex-level area, we constructed bivariate models that decomposed the observed phenotypic covariance between each vertex and standardized global SA. The statistical genetic approach was similar to that described previously for CT (Schmitt et al., 2009). Briefly, models were statistical genetic extensions of the Cholesky decomposition, which factors any symmetric-positive definite matrix into a lower triangular matrix postmultiplied by its transpose (Neale and Cardon, 1992). This approach allows for the covariance between two phenotypes to be decomposed into that owed to shared genetic or environmental sources but places few a priori constraints on the data. Mathematically, the $2 \times 2$ phenotypic variance-covariance matrix $(P)$ and expected cross-twin variance-covariance matrices $\left(\operatorname{Cov}_{M Z}, \operatorname{Cov}_{D Z}\right)$ can be expressed as follows:

$$
\begin{gathered}
P=\left(A * A^{\prime}\right)+\left(C * C^{\prime}\right)+\left(E * E^{\prime}\right) \\
\operatorname{Cov}_{M Z}=\left(A * A^{\prime}\right)+\left(C * C^{\prime}\right) \\
\operatorname{Cov}_{D Z}=\frac{1}{2}\left(A * A^{\prime}\right)+\left(C * C^{\prime}\right)
\end{gathered}
$$

Where $\mathrm{A}, \mathrm{C}$, and $\mathrm{E}$ represent $2 \times 2$ lower triangular matrices with three free parameters each, e.g.:

$$
\boldsymbol{A}=\left[\begin{array}{cc}
\mathrm{a}_{11} & 0 \\
\mathrm{a}_{21} & \mathrm{a}_{22}
\end{array}\right]
$$

Similar to the univariate case, the observed cross-sibling variance-covariance matrices can be used to solve for each individual parameter estimate. Genetic and environmental correlations between total SA and each vertex $i$ were calculated as follows: 


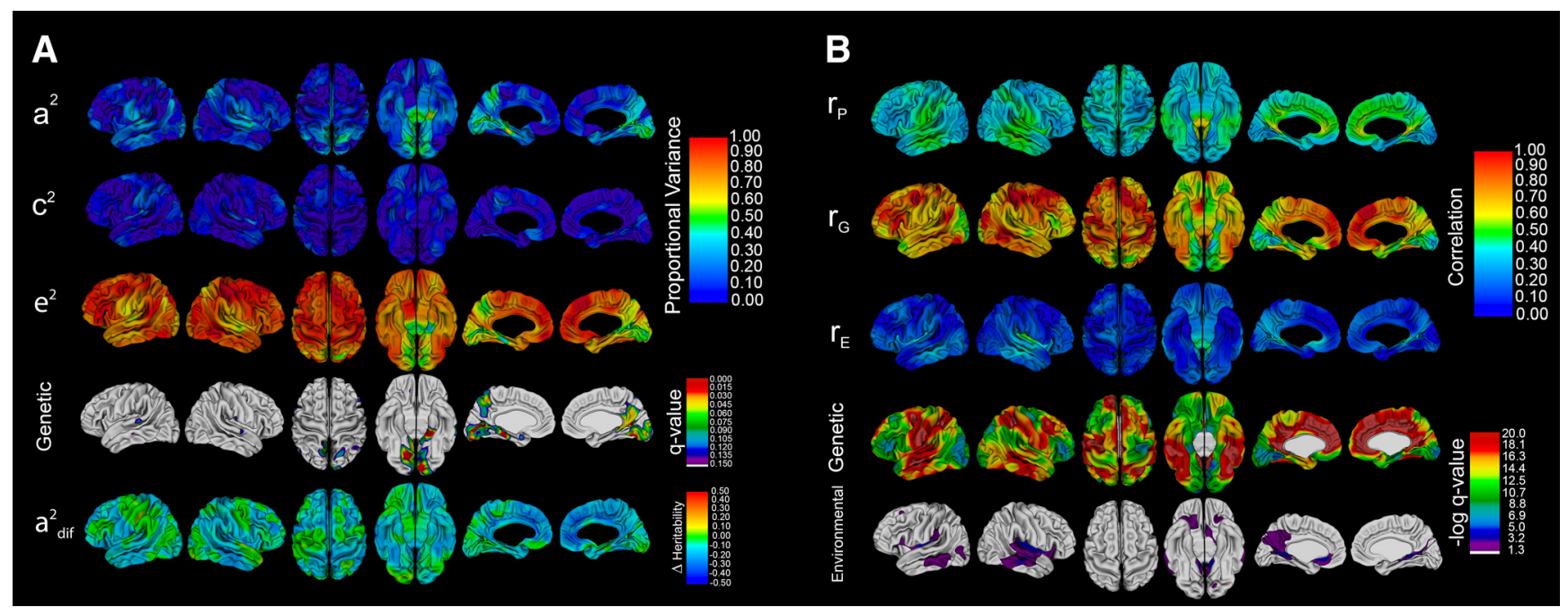

Figure 2. Global effects on areal expansion. $A$, Results from univariate variance decomposition after including total cerebral $S A$ as a covariate. The shared environment was not significant in these models. $a_{d i f}^{2}$ plots regional differences in heritability relative to the original model presented in Figure 1; negative values indicate regions where heritability decreased after including the global covariate. $\boldsymbol{B}$, Results from bivariate analyses directly examining the relationship between areal expansion and total SA. Regional phenotypic $\left(r_{\mathrm{p}}\right)$, genetic $\left(r_{\mathrm{G}}\right)$, and unique environmental $\left(r_{\mathrm{E}}\right)$ correlations are provided, as well as tests assessing the statistical significance of genetic and environmental covariance.

$$
r_{G_{i}}=\frac{a_{G_{i}, t o t S A}}{\sqrt{a_{G_{i}} * a_{t o t S A}}}
$$

Where $a_{G i, t o t S A}=\mathrm{a}_{11} * \mathrm{a}_{21}$ and represents the genetic covariance between the $i^{\text {th }}$ vertex and total SA, $a_{G i}=a_{11}{ }^{2}$ the genetic variance at the $i^{\text {th }}$ vertex, and $a_{\text {totSA }}=\mathrm{a}_{21}{ }^{2}+\mathrm{a}_{22}{ }^{2}$ the genetic variance in total SA. The phenotypic $\left(r_{\mathrm{P}}\right)$ and environmental $\left(r_{\mathrm{E}}\right)$ correlations were estimated similarly.

To quantify similarities between shared genetic effects on SA and hotspots of primate evolution, we compared our estimates of $r_{\mathrm{G}}$ to vertexlevel measures of differential cortical expansion in the human relative to macaque (Hill et al., 2010). This right hemisphere map (Evo) was transformed into CIVET space via methods described previously (Reardon et al., 2018). We then tested for intermap spatial correspondence via spatial permutation, also referred to as the "spin" test (Alexander-Bloch et al., 2018). Briefly, cross-vertex Pearson's correlations for each pair of measures $\left(r_{\mathrm{G}}\right.$ and Evo) were plotted against a null distribution that was described by 1000 spatially permuted values. This test is advantageous because it controls for both multiple testing and spatial autocorrelations. We also constructed $r_{\mathrm{G}}$-Evo concordance maps by identifying vertices that were $>50$ th centile in both metrics, and similarly for vertices $>75$ th centile for both metrics. We repeated this approach (i.e., CIVET transformation, spatial permutation, concordance maps) to the neurodevelopmental expansion data from Hill et al. (2010) (Devo), a map derived from 12 healthy term infants compared with 12 healthy young adult controls. To facilitate subjective visual comparisons between datasets, vertex-level $Z$ scores for all three maps $\left(r_{\mathrm{G}}\right.$, Evo, Devo $)$ were also calculated.

Prior studies have shown strong genetic correlations between contralateral homologs for CT (Schmitt et al., 2009). To examine interhemispheric covariance for SA, we constructed a bivariate model that examined the relationships between the $i$ th vertex in the left hemisphere with its contralateral homolog in the right hemisphere. In these models, we controlled global factors by including total cerebral SA as a covariate.

Similarly, to assess for regionally specific shared genetic influences on SA and CT in children, we performed genetically informative Cholesky decomposition incorporating both measures at each vertex (i.e., a bivariate model with the $i$ th vertex-level measure of both SA and CT), adjusting for sex and linear and nonlinear effects of age. Finally, we used bivariate models to examine the shared genetic influences between vertex-level SA and FSIQ.

ROI-based SA analyses. The scale of measurement has been shown to influence neuroimaging phenotypes, including measures of SA heritability in adults (Patel et al., 2018). Vertex-level measures also suffer from a higher risk of Type II error due to the need for multiple testing correction, problems that are substantially attenuated with an ROI-based approach. Therefore, to examine the effects of genetics of SA at an intermediate level of resolution between global and vertex-level measures, we reanalyzed our data by assigning vertex measures to 1 of 308 ROIs. These ROIs were based on the 68 regions of FreeSurfer's DesikanKillany atlas (Desikan et al., 2006). The Desikan-Killany parcellations were sub-parcellated into $\sim 500 \mathrm{~mm}^{2}$ ROIs via a backtracking algorithm (Romero-Garcia et al., 2012). This approach preserved the original anatomical boundaries while both (1) increasing spatial resolution and (2) increasing the uniformity of the size of each ROI. Variance decomposition for SA was then performed for univariate ACE models (with and without a global covariate), similar to vertex-level measures. Bivariate models testing for both CT-SA and CT-IQ covariance were also performed for each ROI. Multiple testing was controlled with FDR.

\section{Results}

\section{Heritability of global and regional SA}

Total cerebral SA was highly heritable, with $>85 \%$ of the total phenotypic variance attributable to additive genetic factors $\left(\mathrm{a}^{2}=\right.$ $\left.0.86, \mathrm{c}^{2}=0.04, \mathrm{e}^{2}=0.10\right)$; additive genetic effects were statistically significant $\left(\chi^{2}=84.3, p<0.0001\right)$, but shared environmental effects were not. Heritabilities of vertex-level measures were substantially lower, with strong regional variability in the heritability of the cortical sheet (Fig. 1). Regions of highest heritability were in the medial orbital cortex and precuneus, with relatively strong genetic influences also observed in the inferior precentral and postcentral gyri. Modest heritability was also seen in the lateral and inferior temporal lobes. Additive genetic effects were statistically significant in the bilateral medial occipital lobes and precuneus, anterior cingulate gyri and sulci, perisylvian precentral and postcentral gyri, and superior and middle temporal gyri. Contributions of the shared environment were substantially lower, with no regions reaching statistical significance. Statistically significant familial covariance (i.e., combined additive genetic and shared environmental covariance) mirrored genetic probability maps.

\section{Relationships to total SA}

After including total SA as a regressor, the heritability of vertexlevel areal expansion substantially decreased in most brain re- 


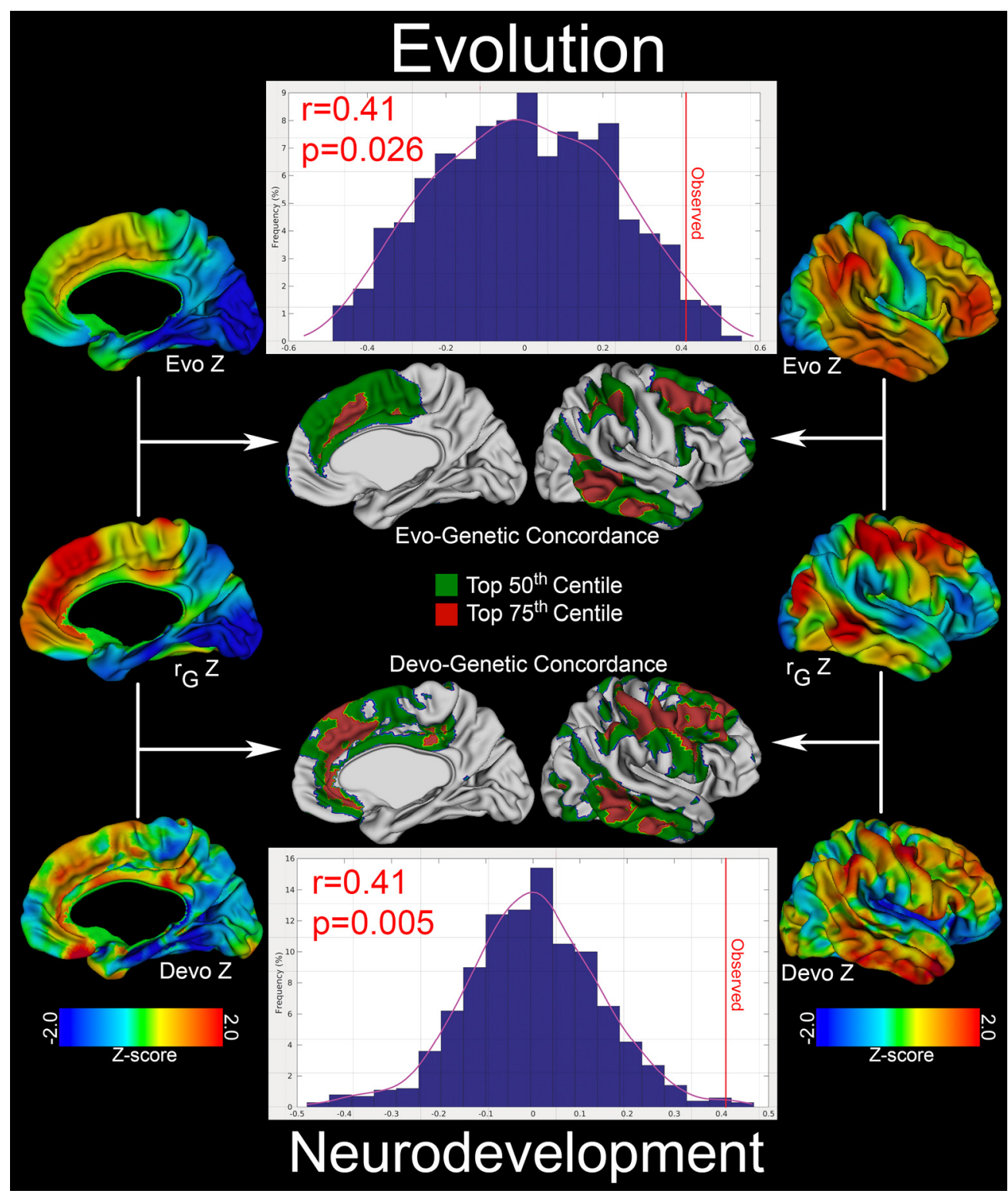

Figure 3. Global genetic influences on SA compared to evolutionary and neurodevelopmental expansion. Evolutionary (top, Evo) and neurodevelopmental (bottom, Devo) maps of cortical expansion from Hill et al. (2010) compared with genetic correlations between total $S A$ and vertex-level areal expansion $\left(r_{\mathrm{G}}\right)$. Standardized (Z-transformed) maps are shown for all measures (along figure margins). Concordance maps (middle) indicate vertices where values were greater than the 50th (green) or 75th (red) centile for both $r_{\mathrm{G}}$ and either Evo or Devo. Histograms from spatial permutation analysis for both Evo-Genetic (top) and Devo-Genetic (bottom) correspondence are also provided.

gions. However, the overall pattern was similar, with the most heritable areas again noted posteriorly and inferiorly (Fig. 2A). Statistically significant additive genetic effects were again observed in occipital and inferior temporal regions, including left parahippocampal and lingual gyri, right fusiform gyrus, and the bilateral calcarine fissures. Shared environmental effects were again substantially lower relative to genetic effects and did not reach statistical significance at any vertex.

These decreases in heritability when total SA was added as a covariate implied that global genetic factors were important contributors to vertex-level genetic variation. When the relationships between global and vertex-level SA were examined via bivariate models, we observed strong genetic correlations throughout the brain despite modest phenotypic correlations (Fig. 2B). The highest genetic correlations were seen in the medial superior frontal gyrus, paracentral lobule, cingulate, and lateral frontal and temporal cortex. Environmental correlations were significantly lower and approximated 0 throughout most of the brain. The influence of shared genetic factors between local and global SA were statistically significant throughout the entire brain but were highest in the bilateral parasagittal frontal and parietal lobes, bilateral fusiform gyri, and the perisylvian cortex.

The regions of the cerebrum with the largest genetic correlations between global SA and areal expansion were similar to hotspots for evolutionary expansion (Fig. 3). The parasagittal frontal lobe, dlPFC, and inferolateral temporal lobes demonstrated relatively strong effects in both metrics relative to other regions of the brain. The concordance between genetic and evolutionary maps was statistically significant $\left(p_{\text {SPIN }}=0.026\right)$. Similarly, comparison between genetic correlations and neurodevelopmental expansion demonstrated strong concordance in parasagittal frontal lobe, dlPFC, and inferolateral temporal lobes and 


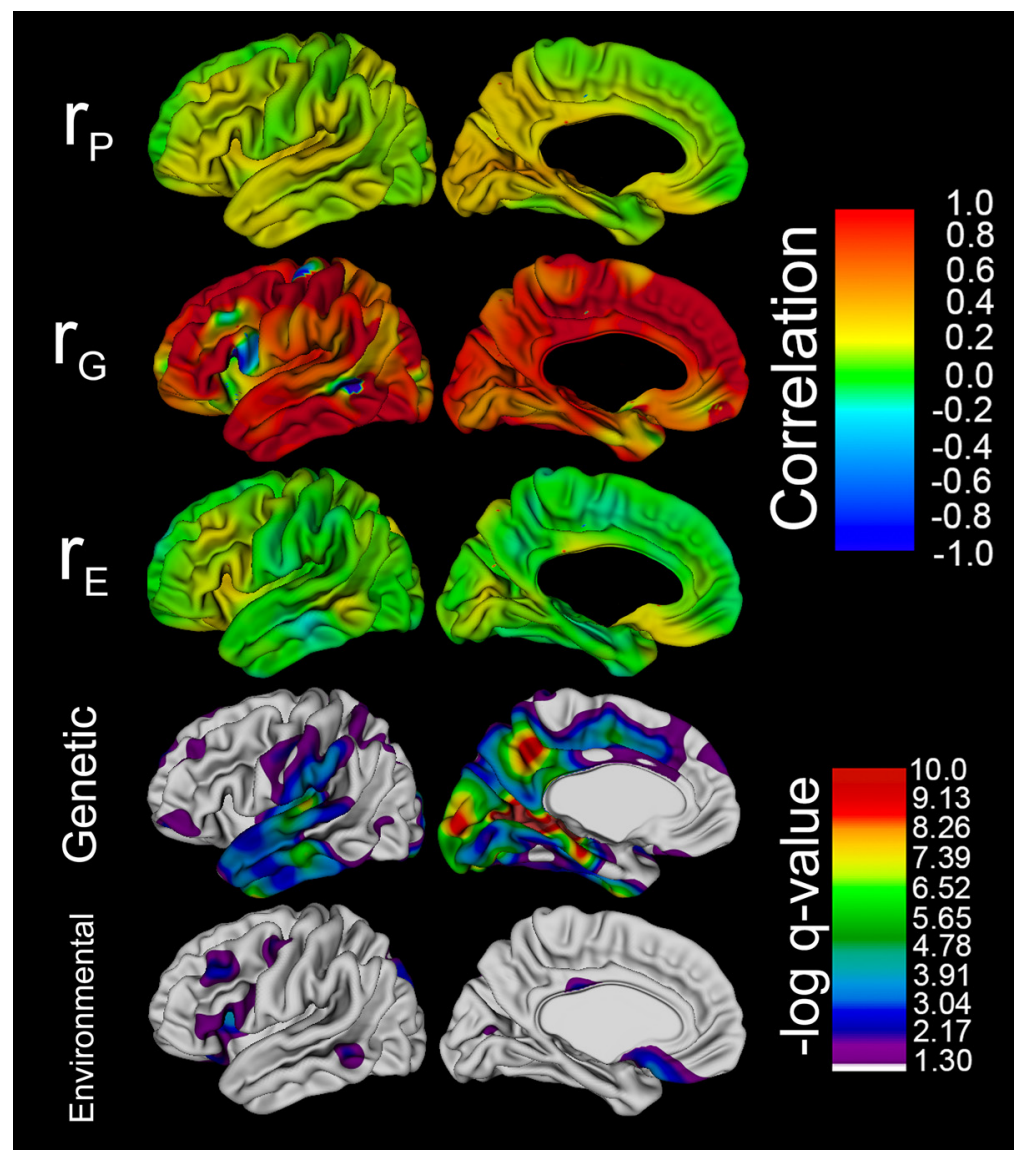

Figure 4. Interhemispheric correlations in areal expansion. Results of bivariate models examining correlations between vertexlevel homologs in the contralateral cortex projected onto the left hemisphere.

additionally the precentral and postcentral gyri. Neurodevelopmental-genetic spatial concordance was also statistically significant $\left(p_{\text {SPIN }}=0.005\right)$.

\section{Laterality}

Cross-hemisphere vertex correlations are shown in Figure 4. There were modest positive interhemispheric phenotypic correlations in the lateral frontal and temporal lobes, parasagittal occipital lobe, and precuneus. Genetic correlations between homologous vertices were substantially higher in magnitude throughout the entire cortex and were generally positive. Small areas of strong negative genetic correlations (i.e., genetic factors that increase left-sided SA decrease right, and vice versa) were seen in the posterior inferior frontal cortex and posterior middle temporal gyrus, although neither reached statistical significance. Significant shared interhemispheric genetic factors were seen throughout the temporal lobe, precuneus, and medial occipital lobe.

\section{Genetically mediated relationships between SA and CT}

The heritability of global mean CT was substantially lower than for total SA $\left(\mathrm{a}^{2}=0.44, \mathrm{c}^{2}=0.00, \mathrm{e}^{2}=0.56\right)$, but nevertheless additive genetic factors had a statistically significant influence on this phenotype $\left(\chi^{2}=8.4, p=0.0018\right)$. The genetic correlation between these global measures was moderate in magnitude and highly significant $\left(r_{\mathrm{G}}=0.63, \chi^{2}=67.1, p<0.0001\right)$. There was notable regional variability in the shared genetic influences on vertex-level measures of SA and CT (Fig. 5). The strongest genetic correlations were in the bilateral dlPFC, perisylvian pa- rietal and temporal lobes, cingulate, right paracentral lobule, and left precuneus, where they approached unity. Statistically significant genetic covariances between SA and CT were observed in the bilateral dlPFC, inferior precentral and postcentral gyri, bilateral superior temporal gyri, cingulate, right paracentral lobule, and left precuneus.

\section{SA and intelligence}

There were modest correlations between global cerebral SA and FSIQ $\left(r_{\mathrm{P}}=0.18, \chi^{2}\right.$ $=17.9, p=0.0001 ; r_{\mathrm{G}}=0.20, \chi^{2}=15.8$, $p=0.0001)$. On the vertex level, weak $\left(r_{\mathrm{P}}\right.$ $<0.3$ ) but generally positive phenotypic correlations between areal expansion and FSIQ were seen throughout the cerebral hemispheres bilaterally (Fig. 6). In contrast, there were strong genetic correlations localized to the left supramarginal gyrus and, to a lesser extent, the perisylvian cortex of the left frontal and temporal lobes and middle temporal gyrus. Genetically mediated SA-FSIQ covariance was statistically significant in the left supramarginal gyrus, inferior precentral and postcentral gyri, middle temporal gyrus, and precuneus. There was marked asymmetry in the strength of correlations with FSIQ; correlations in the right hemisphere were substantially weaker and did not reach statistical significance.
ROI-based analyses

In general, ROI-level analyses using sub-parcellation of the Desikan-Killany atlas produced very similar patterns to those at the vertex level. The highest heritability in SA was again observed in the parasagittal occipital lobe, precuneus, anterior cingulate, and inferior temporal cortex (Fig. 7). Effects from the shared environment were not statistically significant. Patterns of phenotypic, genetic, and environmental correlations between global SA and ROIs were also similar to those at the vertex level (Fig. 8); genetic correlations were high for most of the cerebral surface, with the notable exception of the medial occipital lobes. In the dlPFC, genetic correlations were somewhat lower than those at the vertex level. Probability maps were similar for ROI and vertex-level approaches. Patterns of CT-SA and FSIQ-SA covariance at the ROI level were also similar to our higherresolution analyses (Figs. 9, 10); we again observed strong, asymmetric, and highly significant genetic correlations between FSIQ and SA in the left supramarginal gyrus and, to a lesser extent, in the left frontal operculum.

\section{Discussion}

In this manuscript, we present a systematic analysis of the genetic influences on cerebral SA in children. We found the strongest genetic effects in the posterior and parasagittal cortex, including cuneus, precuneus, and fusiform gyrus. Heritability patterns were strikingly similar to those seen in newborns despite differences in scan acquisition, image processing, and statistical design (Jha et al., 2018). As in the current study, Jha et al. (2018) found 


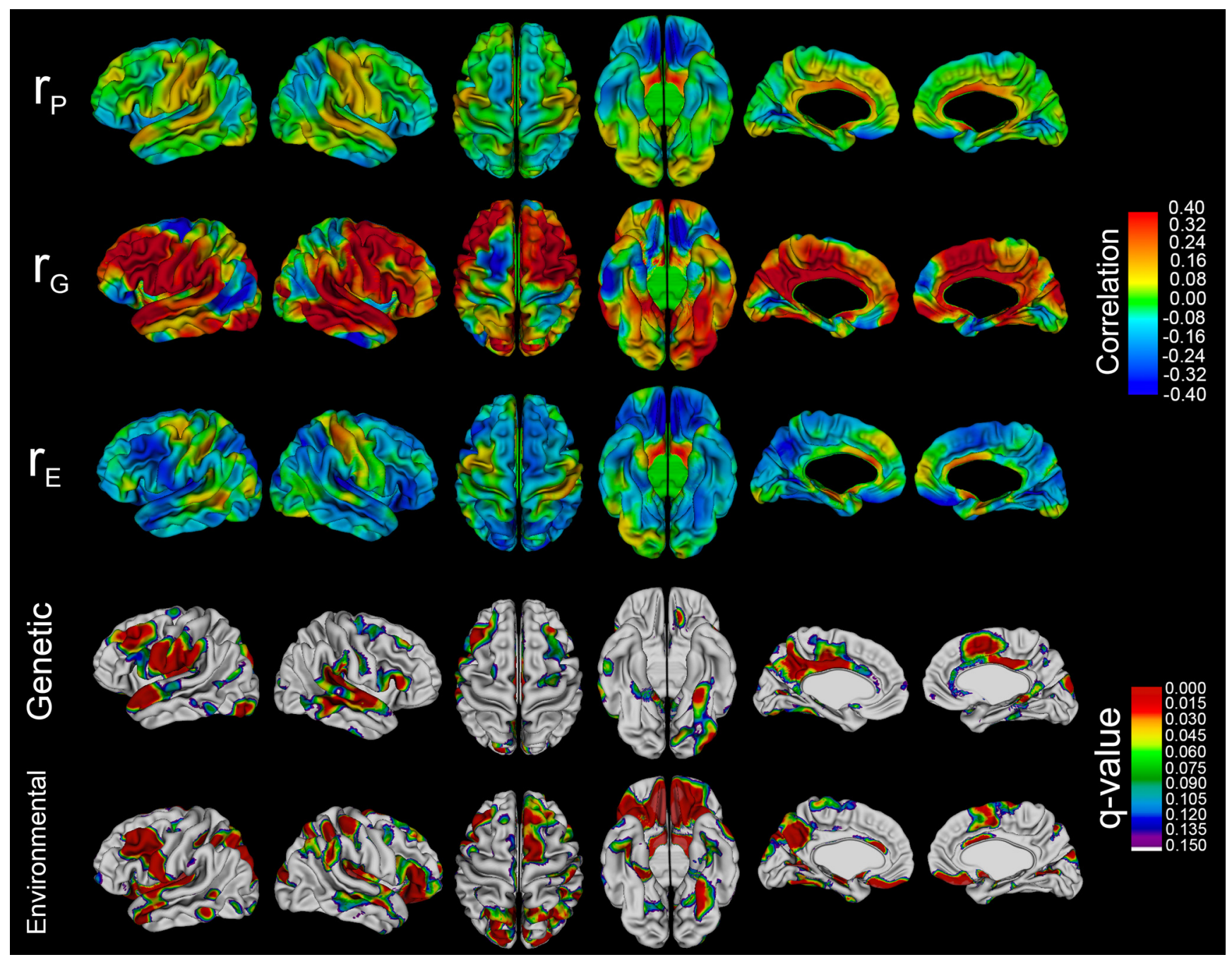

Figure 5. Shared genetic relationships between areal expansion and CT. Regional phenotypic $\left(r_{\mathrm{p}}\right)$, genetic $\left(r_{\mathrm{G}}\right)$, and environmental $\left(r_{\mathrm{E}}\right)$ correlations are shown, as well as tests assessing the statistical significance of genetic and environmental covariance.

predominantly low regional heritability estimates, with strongest values localizing to the parasagittal posterior cerebrum, occipitotemporal cortex, and perisylvian regions. A study of 928 -year-old twins similarly found statistically significant SA heritability in the posterior parasagittal cerebrum and inferior temporal lobe (Yoon et al., 2012). In a young adult sample (mean age 22.27 years), regional heritability was also strongest in the occipital lobes (Strike et al., 2019). Our heritability patterns differed to a greater extent compared with 838 predominantly young and middle-aged adults (McKay et al., 2014), which additionally identified strong heritability in the medial frontal lobes. In the Vietnam Era Twin Study of Aging (VETSA) cohort (mean age 55.8 years), estimates were much higher and less regionally variable (Eyler et al., 2011, 2012). Although these analyses were all cross-sectional, considered together they imply that SA heritability increases with age, a phenomenon that we have observed when examining CT longitudinally (Schmitt et al., 2014).

The most heritable regions of areal expansion generally conform to visual cortex, including both dorsal and ventral streams (Goodale and Westwood, 2004). An enlarged visual system distinguishes primates from other mammals (Northcutt and Kaas, 1995), and regions of visual cortex demonstrate correlated evolution (Barton, 2007). Perhaps surprisingly, these heritability patterns largely correspond to cortical regions that have had the least evolutionary expansion in humans relative to other primates (Hill et al., 2010). Over evolutionary timescales, genes influencing phenotypes under strong directional selection should reach allelic fixation; thus, while a trait may remain under genetic control, genetically mediated variance will be purged. However, other factors, such as balancing selection, mutation, pleiotropy, and temporal or geographic variation in selective pressures, could potentially maintain genetic variance in the population indefinitely (Barton and Keightley, 2002). Moreover, traits with greater dimensional complexity (i.e., the primate brain) are expected to adapt at substantially slower rates than simpler traits (Orr, 2000).

\section{Global genetic factors influence evolutionarily novel}

brain regions

We found strong genetic influences on total SA in children and adolescents, with $>85 \%$ of the variance attributable to genetic factors. Strong heritability of this global measure appears reasonably consistent across studies, including newborns $\left(\mathrm{a}^{2}=0.78\right)$ (Jha et al., 2018), older adults $\left(\mathrm{a}^{2}=0.89\right)$ (Panizzon et al., 2009), and nonhuman primates $\left(\mathrm{a}^{2}=0.73\right)$ (Rogers et al., 2007). When total SA was included as a covariate, genetic signal decreased through most of the cortex, implying that the global genetic factor was influencing individual differences at the vertex level. This 


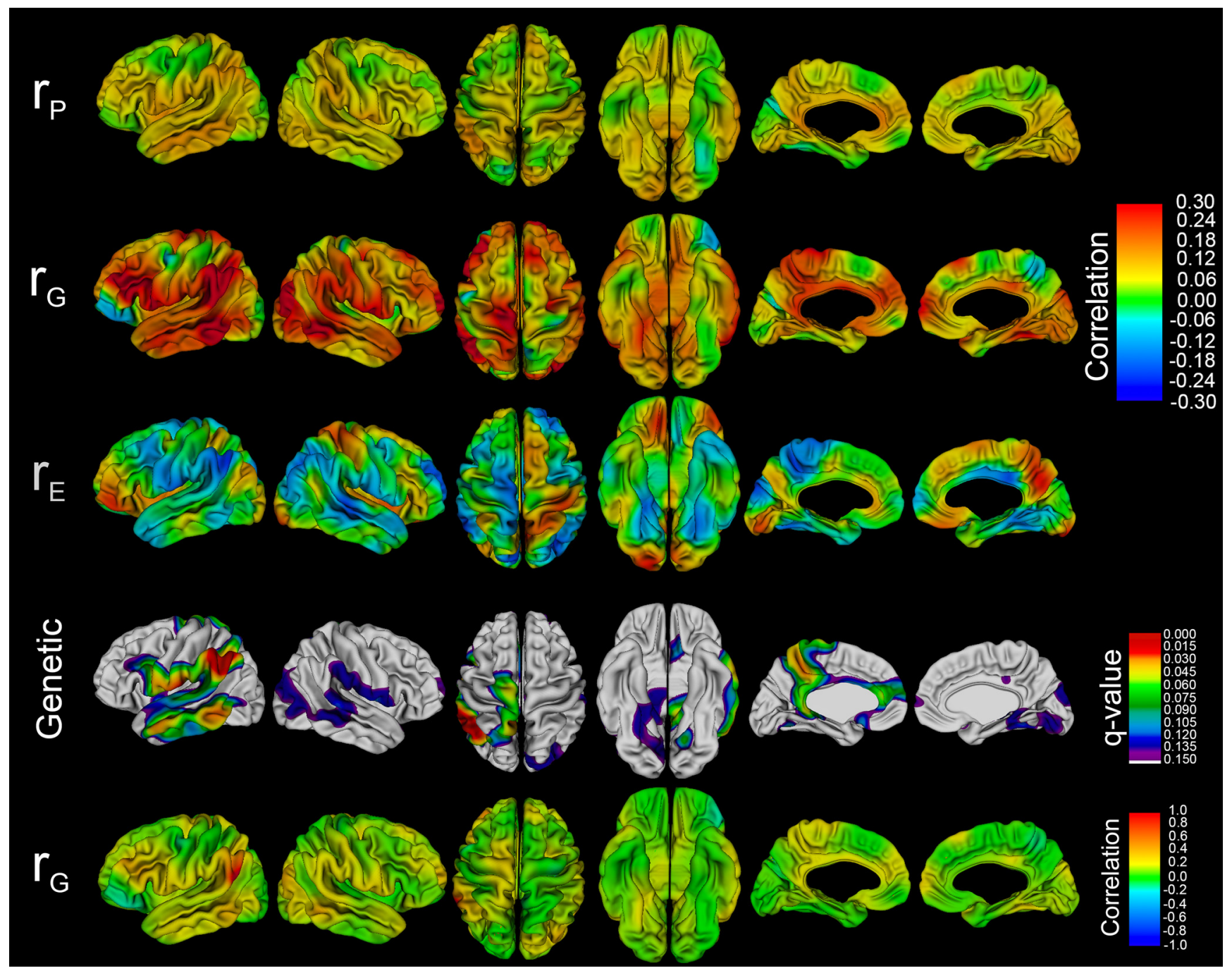

Figure 6. Genetically mediated correlations with intelligence. Vertex-level phenotypic $\left(r_{\mathrm{p}}\right)$, genetic $\left(r_{\mathrm{G}}\right)$, and environmental $\left(r_{\mathrm{E}}\right)$ correlations are shown (top) along with a probability map of statistically significant shared genetic influences. Environmental covariance between SA and FSIQ was not statistically significant at any vertex. Because genetic correlations were much stronger than phenotypic correlations, $r_{G}$ is plotted a second time with a wider scale (bottom).

finding was confirmed with dedicated models explicitly examining global-local SA relationships, where genetic correlations approached unity throughout much of the cortex. Those regions with the strongest genetic correlations also have the highest rates of areal expansion on both developmental and evolutionary timescales (Hill et al., 2010; Reardon et al., 2018); our results indicate that these effects may be genetically mediated. The presence of a global genetic factor also has implications for genomic studies, as examination of SA at high levels of neuroanatomic resolution may not be worth the associated drop in power owed to corrections for multiple testing.

The principal exceptions to strong global effects were the parasagittal occipital lobe and precuneus, which were the least impacted by the global covariate despite being among the most heritable of all regions. These areas also rank among the least affected by evolutionary expansion (Reardon et al., 2018), a somewhat unexpected finding considering that areas with the highest CT heritability are among the most evolutionarily novel (Schmitt et al., 2008). We also observed that the strongest interhemispheric genetic correlations were in visual cortex. Ipsilateral between-region genetic correlations are also strongest within the occipital lobe (Strike et al., 2019). These findings suggest that, at least in younger individuals, the underlying genetic architecture of the occipital lobe is largely distinct from the remainder of the brain, with strong genetic overlap between areas involved in visual perception.

\section{Shared genetic influences on SA and CT}

We observed substantial overlap in the genetic factors influencing total cerebral SA and mean CT $\left(r_{\mathrm{G}}=0.63\right)$, a finding that contrasts with the VETSA $\left(r_{\mathrm{G}}=-0.15\right)$, Genetics of Brain Structure and Function $\left(r_{\mathrm{G}}=-0.15\right)$, and Queensland Twin Imaging $\left(r_{\mathrm{G}}=-0.21\right)$ adult samples (Panizzon et al., 2009; Winkler et al., 2010; Strike et al., 2019). Based on these prior results, it has been assumed that $\mathrm{CT}$ and SA are genetically orthogonal. However, a strong CT-SA genetic correlation $\left(r_{\mathrm{G}}=0.65\right)$ has also been recently reported in newborns (Jha et al., 2018). In light of these new findings, a dynamic relationship between SA and CT needs to be considered a possibility, with stronger genetic coupling earlier in life than that seen after maturity.

CT and SA are both thought to be largely dependent on rates of cellular proliferation of neuronal progenitors; whereas symmetric divisions of precursors increase the number of radial units in the cortex (thus increasing SA), asymmetric divisions between 


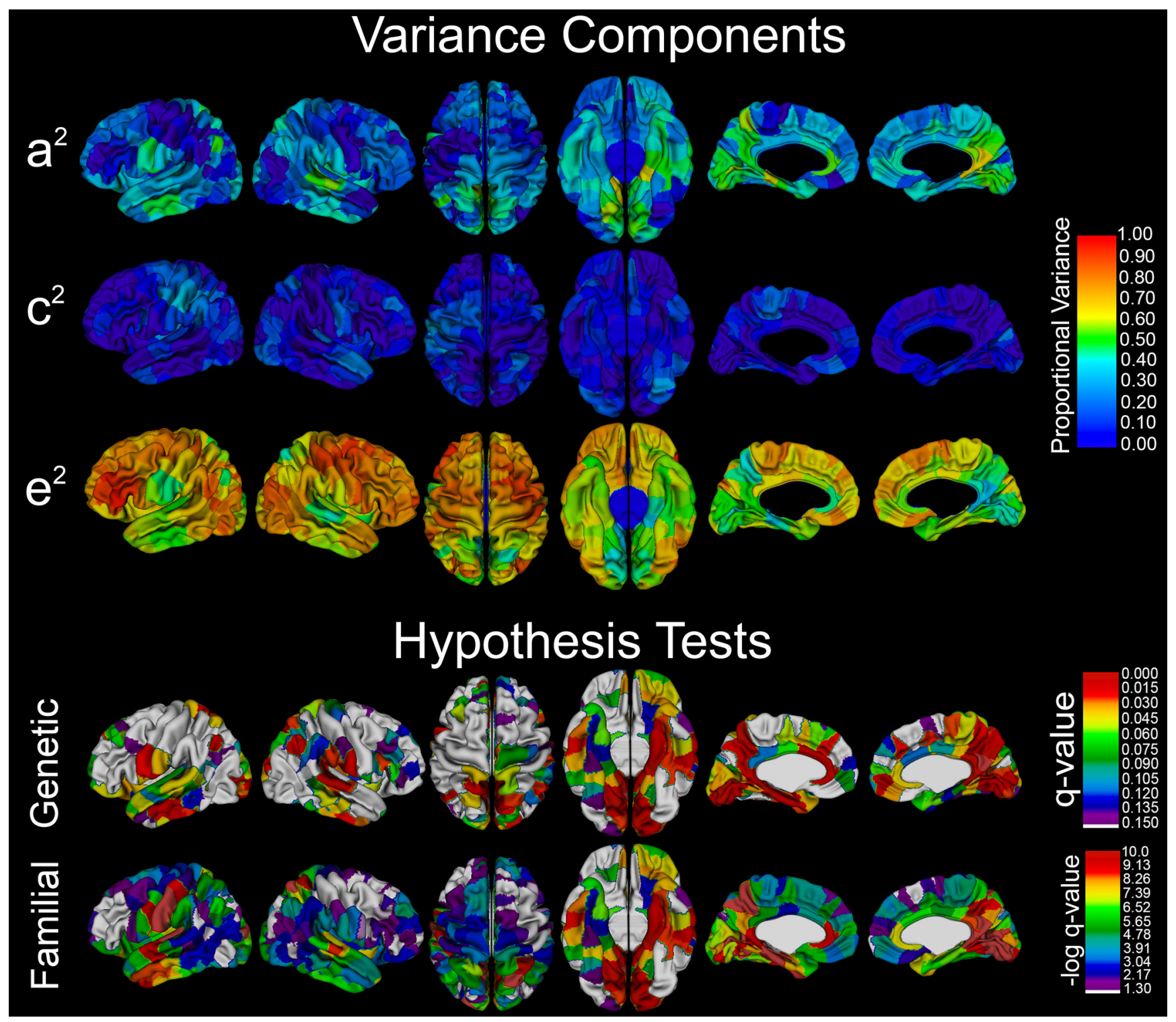

Figure 7. Heritability of cerebral SA for 308 sub-ROls based on the Desikan-Killany atlas. Maximum likelihood estimates and FDR-corrected probability maps for genetic and familial variance are also shown. Similar to vertex-level measures, there were no statistically significant shared environmental effects after correction for multiple testing.

precursors and daughter cells within units are thought to affect CT by influencing the number of cells per radial unit (Rakic, 1988; Rubenstein and Rakic, 1999; Amlien et al., 2016). Genetic independence between SA and CT is therefore conceptually appealing because it conforms to our traditional understanding of neurogenesis. However, newer research has found that the neurodevelopmental relationships between these measures are more nuanced than previously understood (Kriegstein et al., 2006). For example, intermediate progenitor cells have been identified that may influence the expansion of both CT and SA (Pontious et al., 2008). It is also important to consider that other developmental mechanisms influence both metrics, including apoptosis, neuropil growth, and mechanical tension (Van Essen, 1997; Krubitzer and Kahn, 2003; Toro and Burnod, 2005), all of which are likely influenced by genetics.

When the relationships between arealization and thickness were examined on the vertex level, we found substantial regional variation, with the strongest positive genetic correlations in the perisylvian cortex, left dlPFC, parasagittal frontal lobes, and cin- gulate cortex. Although many of these regions correspond to areas of evolutionary expansion, there are notable exceptions, including greater than expected genetic correlations in primary motor cortex and less than expected correlations in the posterolateral temporal lobe. Nevertheless, the similar patterns may be indicative of genetic variants influencing both metrics in these regions. Overall, the strength of genetic correlations that we observed was stronger compared with Strike et al. (2019), who reported weak genetically mediated relationships at the gyral level. Given the differences in age between samples, neurodevelopmental factors may explain the discrepancies between studies and warrants further investigation.

Genetic factors drive relationships between SA and intelligence in children

We observed modest phenotypic correlations between cortical arealization and intelligence that were stronger in the left cerebrum. Although numerous prior studies have found correlations between constructs of intelligence and both volume and CT 


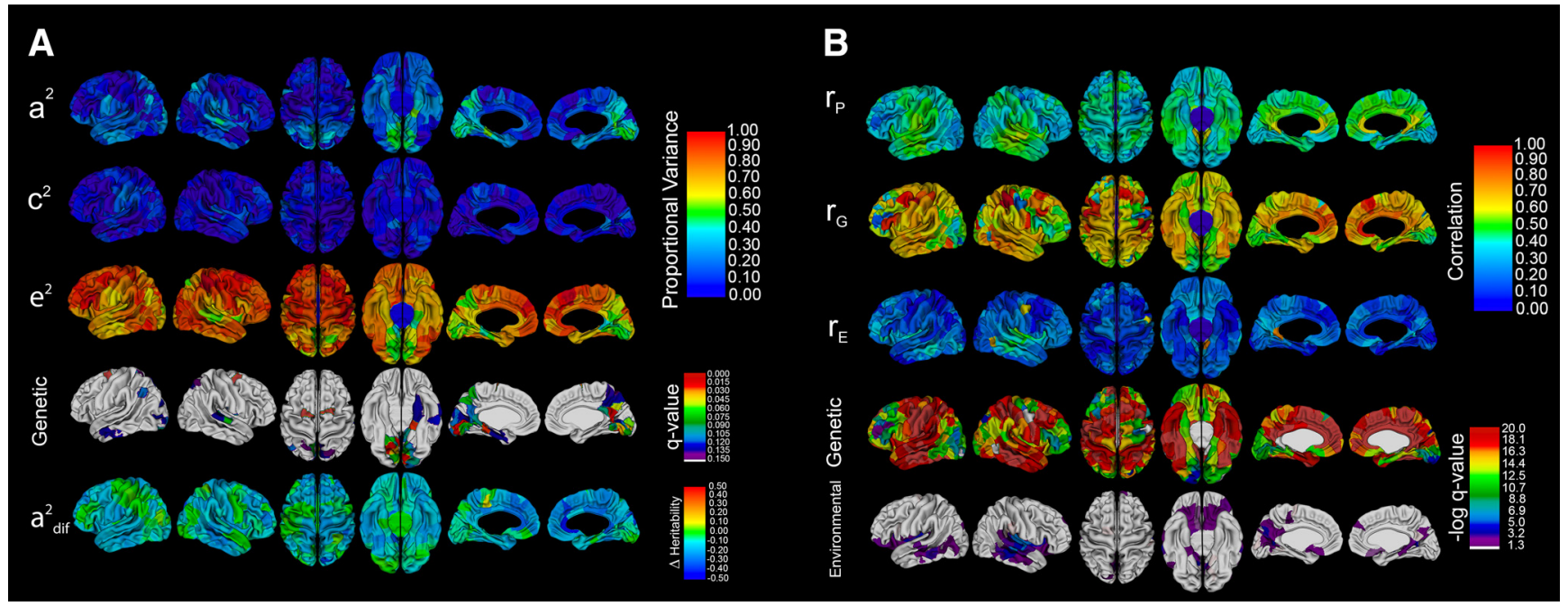

Figure 8. Genetic effects of global SA on regional parcellations. $\boldsymbol{A}$, Results from univariate ACE models after including total cerebral $S A$ as a covariate. $a_{d i f}^{2}$ plots ROI-level differences in heritability relative to the original model without a global covariate. $\boldsymbol{B}$, Results from bivariate analyses that directly model the relationship between regional $S A$ and total $S A$.

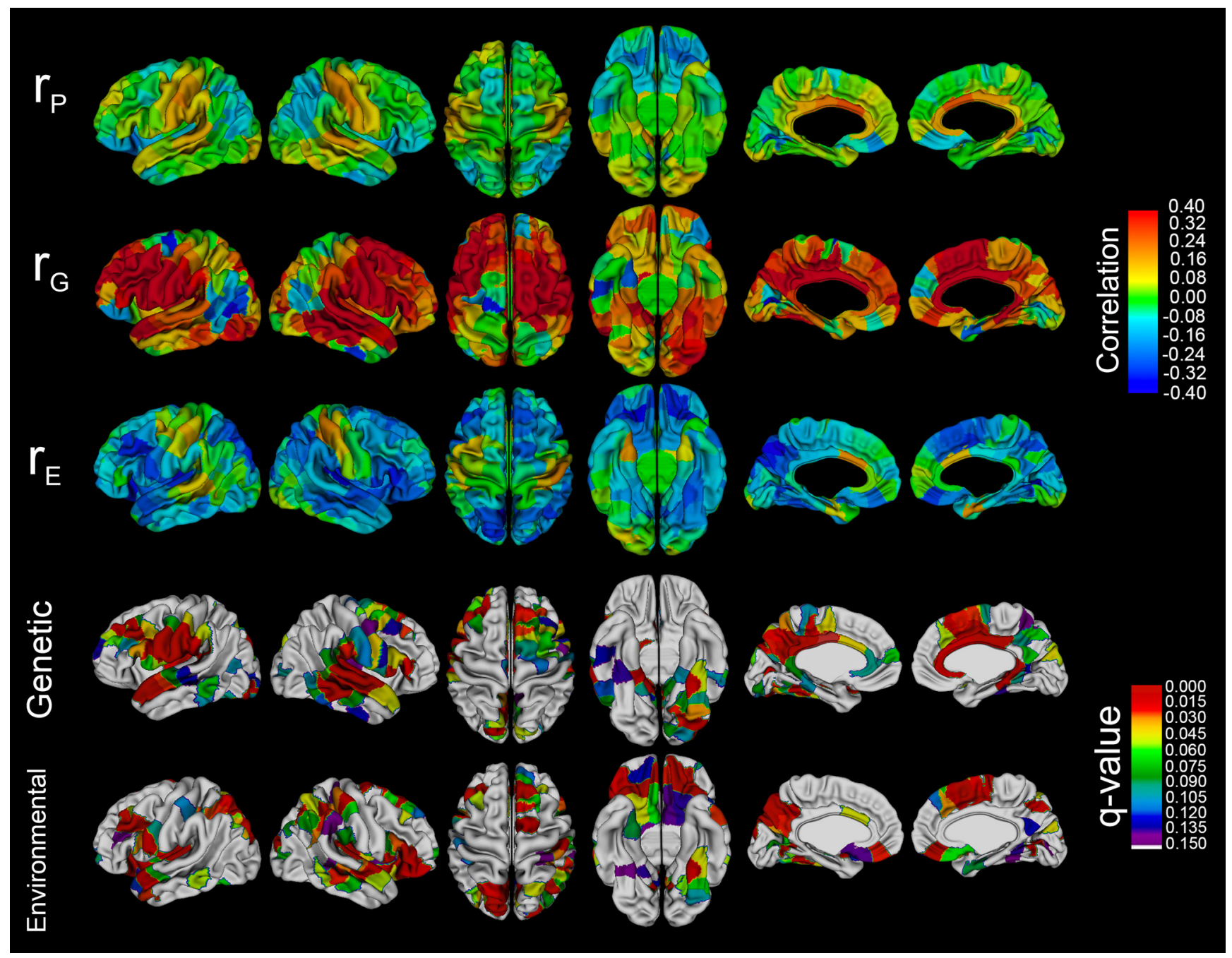

Figure 9. Shared genetic relationships between areal expansion and CT at the ROl level. Regional phenotypic $\left(r_{\mathrm{p}}\right)$, genetic $\left(r_{\mathrm{G}}\right)$, and environmental $\left(r_{\mathrm{E}}\right)$ correlations are shown, as well as tests assessing the statistical significance of genetic and environmental covariance. 


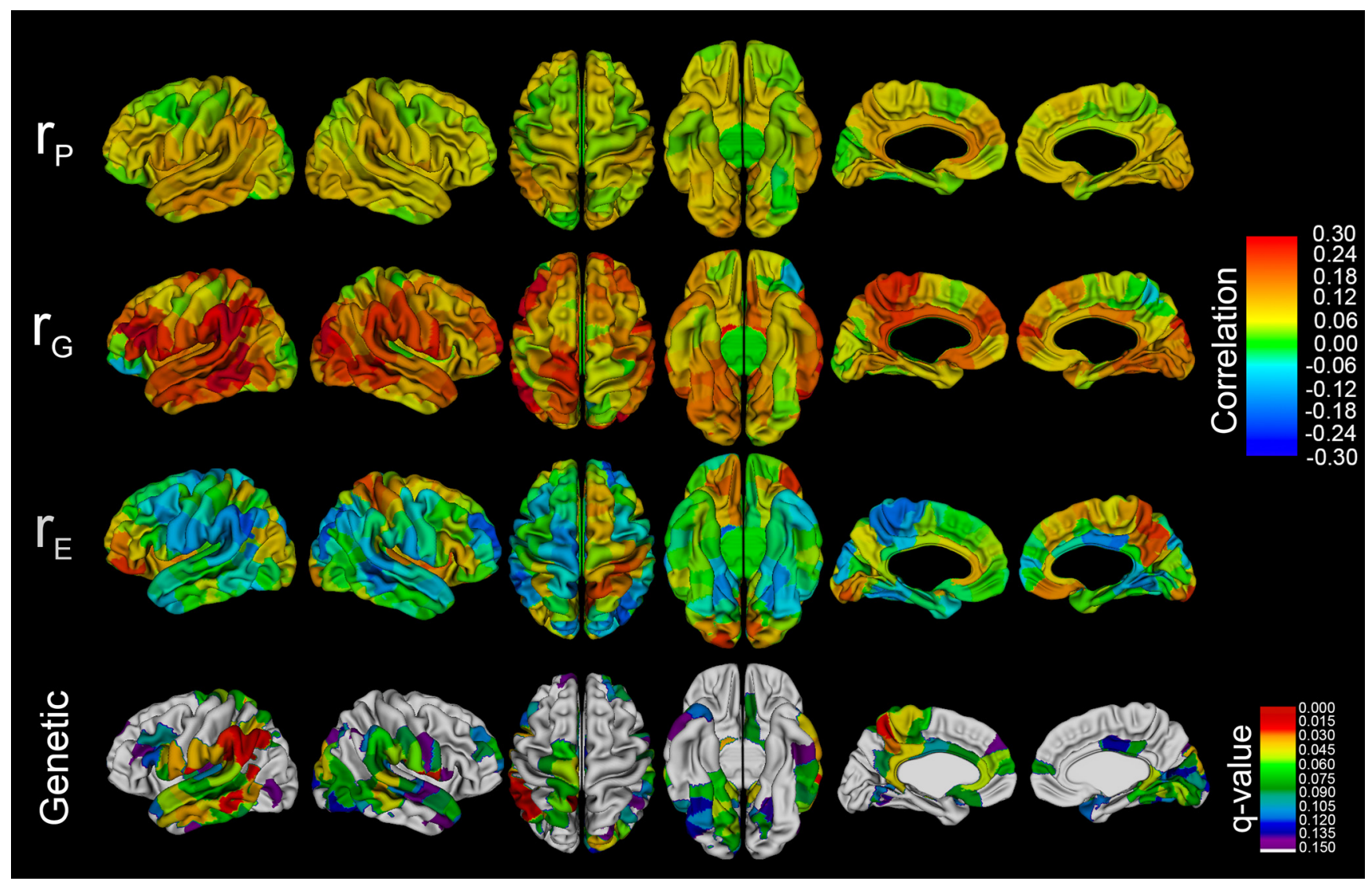

Figure 10. Genetically mediated correlations between intelligence and regional parcellations of cerebral SA. Phenotypic $\left(r_{\mathrm{p}}\right)$, genetic $\left(r_{\mathrm{G}}\right)$, and environmental $\left(r_{\mathrm{E}}\right)$ correlations are shown (top) along with a probability map of statistically significant shared genetic influences. Environmental correlations were not statistically significant after correction for multiple testing.

(Deary et al., 2010), the extant literature on the relationships between SA and intelligence is more limited, particularly in children. Schnack et al. (2015) found that total cortical SA was larger in children with higher FSIQ. In a sample of 449 children aged 4-12 years (Walhovd et al., 2016), there were widespread SAFSIQ associations that generally parallel the regions of strongest phenotypic correlations in the current study. Moreover, when these areas were mapped to the VETSA sample, there was a small $\left(r_{\mathrm{G}}=0.21\right)$ but statistically significant genetic correlation in older adult subjects.

However, to our knowledge, the genetics underlying these relationships has not yet been directly examined in youth. Our data suggest significant asymmetry in genetic factors influencing both cortical arealization and intelligence in children, particularly in the left supramarginal and angular gyri (Brodmann areas $39,40)$ where genetic correlations approached unity. The genetically mediated relationships between FSIQ and SA are very similar to the regions of greatest leftward asymmetry in humans (Lyttelton et al., 2009). Brodmann areas 39 and 40 are both central to the Parieto-Frontal Integration Theory network of regions that have been most associated with performance on cognitive tasks (Jung and Haier, 2007), are critical for receptive language ability, and rank among the most evolutionarily unique regions of the human brain (Carroll, 2003). We also found statistically significant shared genetic effects for two other regions in this network (BA 21, 37), although several other regions (e.g., dlPFC, associative visual cortex) did not reach statistical significance.

In conclusion, these data provide strong evidence that genetic factors drive individual differences in human cerebral SA in children. We also find convincing evidence that global genetic factors influence local SA, as well as genetically mediated brainbehavioral associations that conform to our current understanding of functional neuroanatomy. However, our results also suggest a nuanced and sometimes counterintuitive process influenced by regional, evolutionary, and neurodevelopmental factors that thus far remain poorly understood. Further multivariate, genomic, bioinformatics, and longitudinal studies will be required to understand this remarkably complex structure in greater detail.

\section{References}

Ad-Dab’bagh Y, Lyttelton O, Muehlboeck J, Lepage C, Einarson D, Mok K, Ivanov O, Vincent R, Lerch J, Fombonne E, Evans A (2006) The CIVET image-processing environment: a fully automated comprehensive pipeline for anatomcal neuroimaging research. In: Proceedings of the 12th Annual Meeting of the Organization for Human Brain Mapping (Corbetta M, ed), Florence, Italy.

Alexander-Bloch AF, Shou H, Liu S, Satterthwaite TD, Glahn DC, Shinohara RT, Vandekar SN, Raznahan A (2018) On testing for spatial correspondence between maps of human brain structure and function. Neuroimage 178:540-551.

Amlien IK, Fjell AM, Tamnes CK, Grydeland H, Krogsrud SK, Chaplin TA, Rosa MG, Walhovd KB (2016) Organizing principles of human cortical development thickness and area from 4 to 30 years: insights from comparative primate neuroanatomy. Cereb Cortex 26:257-267.

Barton NH, Keightley PD (2002) Understanding quantitative genetic variation. Nat Rev Genet 3:11-21.

Barton RA (2007) Evolutionary specialization in mammalian cortical structure. J Evol Biol 20:1504-1511.

Boker S, Neale M, Maes H, Wilde M, Spiegel M, Brick T, Spies J, Estabrook R, Kenny S, Bates T, Mehta P, Fox J (2011) OpenMx: an open source extended structural equation modeling framework. Psychometrika 76:306317 . 
Carroll SB (2003) Genetics and the making of Homo sapiens. Nature 422:849-857.

Collins DL, Neelin P, Peters TM, Evans AC (1994) Automatic 3D intersubject registration of MR volumetric data in standardized Talairach space. J Comput Assist Tomogr 18:192-205.

Deary IJ, Penke L, Johnson W (2010) The neuroscience of human intelligence differences. Nat Rev Neurosci 11:201-211.

Desikan RS, Ségonne F, Fischl B, Quinn BT, Dickerson BC, Blacker D, Buckner RL, Dale AM, Maguire RP, Hyman BT, Albert MS, Killiany RJ (2006) An automated labeling system for subdividing the human cerebral cortex on MRI scans into gyral based regions of interest. Neuroimage 31:968-980.

Dominicus A, Skrondal A, Gjessing HK, Pedersen NL, Palmgren J (2006) Likelihood ratio tests in behavioral genetics: problems and solutions. Behav Genet 36:331-340.

Edwards A (1972) Likelihood: an account of the statistical concept of likelihood and its application to scientific inference. Cambridge: Cambridge UP.

Eyler LT, Prom-Wormley E, Panizzon MS, Kaup AR, Fennema-Notestine C, Neale MC, Jernigan TL, Fischl B, Franz CE, Lyons MJ, Grant M, Stevens A, Pacheco J, Perry ME, Schmitt JE, Seidman LJ, Thermenos HW, Tsuang MT, Chen CH, Thompson WK, et al. (2011) Genetic and environmental contributions to regional cortical surface area in humans: a magnetic resonance imaging twin study. Cereb Cortex 21:2313-2321.

Eyler LT, Chen CH, Panizzon MS, Fennema-Notestine C, Neale MC, Jak A, Jernigan TL, Fischl B, Franz CE, Lyons MJ, Grant M, Prom-Wormley E, Seidman LJ, Tsuang MT, Fiecas MJ, Dale AM, Kremen WS (2012) A comparison of heritability maps of cortical surface area and thickness and the influence of adjustment for whole brain measures: a magnetic resonance imaging twin study. Twin Res Hum Genet 15:304-314.

Fjell AM, Westlye LT, Amlien I, Tamnes CK, Grydeland H, Engvig A, Espeseth T, Reinvang I, Lundervold AJ, Lundervold A, Walhovd KB (2015) High-expanding cortical regions in human development and evolution are related to higher intellectual abilities. Cereb Cortex 25:26-34.

Genovese CR, Lazar NA, Nichols T (2002) Thresholding of statistical maps in functional neuroimaging using the false discovery rate. Neuroimage 15:870-878.

Giedd JN, Raznahan A, Alexander-Bloch A, Schmitt E, Gogtay N, Rapoport JL (2015) Child Psychiatry Branch of the National Institute of Mental Health Longitudinal Structural Magnetic Resonance Imaging Study of Human Brain Development. Neuropsychopharmacology 40:43-49.

Goodale MA, Westwood DA (2004) An evolving view of duplex vision: separate but interacting cortical pathways for perception and action. Curr Opin Neurobiol 14:203-211.

Hill J, Inder T, Neil J, Dierker D, Harwell J, Van Essen D (2010) Similar patterns of cortical expansion during human development and evolution. Proc Natl Acad Sci U S A 107:13135-13140.

Jha SC, Xia K, Schmitt JE, Ahn M, Girault JB, Murphy VA, Li G, Wang L, Shen D, Zou F, Zhu H, Styner M, Knickmeyer RC, Gilmore JH (2018) Genetic influences on neonatal cortical thickness and surface area. Hum Brain Mapp 39:4998-5013.

Jung RE, Haier RJ (2007) The parieto-frontal integration theory (P-FIT) of intelligence: converging neuroimaging evidence. Behav Brain Sci 30:135187.

Kim JS, Singh V, Lee JK, Lerch J, Ad-Dab'bagh Y, MacDonald D, Lee JM, Kim SI, Evans AC (2005) Automated 3-D extraction and evaluation of the inner and outer cortical surfaces using a Laplacian map and partial volume effect classification. Neuroimage 27:210-221.

Kriegstein A, Noctor S, Martínez-Cerdeño V (2006) Patterns of neural stem and progenitor cell division may underlie evolutionary cortical expansion. Nat Rev Neurosci 7:883-890.

Krubitzer L, Kahn DM (2003) Nature versus nurture revisited: an old idea with a new twist. Prog Neurobiol 70:33-52.

Lenroot RK, Schmitt JE, Ordaz SJ, Wallace GL, Neale MC, Lerch JP, Kendler KS, Evans AC, Giedd JN (2009) Differences in genetic and environmental influences on the human cerebral cortex associated with development during childhood and adolescence. Hum Brain Mapp 30:163-174.

Lerch JP, Evans AC (2005) Cortical thickness analysis examined through power analysis and a population simulation. Neuroimage 24:163-173.

Lyttelton OC, Karama S, Ad-Dab'bagh Y, Zatorre RJ, Carbonell F, Worsley K, Evans AC (2009) Positional and surface area asymmetry of the human cerebral cortex. Neuroimage 46:895-903.
MacDonald D, Kabani N, Avis D, Evans AC (2000) Automated 3-D extraction of inner and outer surfaces of cerebral cortex from MRI. Neuroimage 12:340-356.

McKay DR, Knowles EE, Winkler AA, Sprooten E, Kochunov P, Olvera RL, Curran JE, Kent JW Jr, Carless MA, Göring HH, Dyer TD, Duggirala R, Almasy L, Fox PT, Blangero J, Glahn DC (2014) Influence of age, sex and genetic factors on the human brain. Brain Imaging Behav 8:143-152.

Neale M, Cardon L (1992) Methodology for genetic studies of twins and families. Dordrecht, The Netherlands: Kluver.

Neale MC, Hunter MD, Pritikin JN, Zahery M, Brick TR, Kirkpatrick RM, Estabrook R, Bates TC, Maes HH, Boker SM (2016) OpenMx 2.0: extended structural equation and statistical modeling. Psychometrika 81:535-549.

Northcutt RG, Kaas JH (1995) The emergence and evolution of mammalian neocortex. Trends Neurosci 18:373-379.

Orr HA (2000) Adaptation and the cost of complexity. Evolution 54:13-20.

Panizzon MS, Fennema-Notestine C, Eyler LT, Jernigan TL, Prom-Wormley E, Neale M, Jacobson K, Lyons MJ, Grant MD, Franz CE, Xian H, Tsuang M, Fischl B, Seidman L, Dale A, Kremen WS (2009) Distinct genetic influences on cortical surface area and cortical thickness. Cereb Cortex 19:2728-2735.

Patel S, Patel R, Park MT, Masellis M, Knight J, Chakravarty MM (2018) Heritability estimates of cortical anatomy: the influence and reliability of different estimation strategies. Neuroimage 178:78-91.

Pontious A, Kowalczyk T, Englund C, Hevner RF (2008) Role of intermediate progenitor cells in cerebral cortex development. Dev Neurosci 30:2432.

Posthuma D, Boomsma DI (2000) A note on the statistical power in extended twin designs. Behav Genet 30:147-158.

R Core Team (2018) R: a language and environment for statistical computing. Vienna: RFoundation for Statistical Computing. http://www.R-project.org/.

Rakic P (1988) Specification of cerebral cortical areas. Science 241:170-176.

Rakic P (2009) Evolution of the neocortex: a perspective from developmental biology. Nat Rev Neurosci 10:724-735.

Reardon PK, Seidlitz J, Vandekar S, Liu S, Patel R, Park MT, Alexander-Bloch A, Clasen LS, Blumenthal JD, Lalonde FM, Giedd JN, Gur RC, Gur RE, Lerch JP, Chakravarty MM, Satterthwaite TD, Shinohara RT, Raznahan A (2018) Normative brain size variation and the remodeling of brain shape in humans. Science 360:1222-1227.

Robbins S, Evans AC, Collins DL, Whitesides S (2004) Tuning and comparing spatial normalization methods. Med Image Anal 8:311-323.

Rogers J, Kochunov P, Lancaster J, Shelledy W, Glahn D, Blangero J, Fox P (2007) Heritability of brain volume, surface area and shape: an MRI study in an extended pedigree of baboons. Hum Brain Mapp 28:576-583.

Romero-Garcia R, Atienza M, Clemmensen LH, Cantero JL (2012) Neuroimage effects of network resolution on topological properties of human neocortex. Neuroimage 59:3522-3532.

Rubenstein JL, Rakic P (1999) Genetic control of cortical development. Cereb Cortex 9:521-523.

Schmitt JE, Eyler LT, Giedd JN, Kremen WS, Kendler KS, Neale MC (2007) Review of twin and family studies on neuroanatomic phenotypes and typical neurodevelopment. Twin Res Hum Genet 10:683-694.

Schmitt JE, Lenroot RK, Wallace GL, Ordaz S, Taylor KN, Kabani N, Greenstein D, Lerch JP, Kendler KS, Neale MC, Giedd JN (2008) Identification of genetically mediated cortical networks: a multivariate study of pediatric twins and siblings. Cereb Cortex 18:1737-1747.

Schmitt JE, Lenroot RK, Ordaz SE, Wallace GL, Lerch JP, Evans AC, Prom EC, Kendler KS, Neale MC, Giedd JN (2009) Variance decomposition of MRI-based covariance maps using genetically informative samples and structural equation modeling. Neuroimage 47:56-64.

Schmitt JE, Neale MC, Fassassi B, Perez J, Lenroot RK, Wells EM, Giedd JN (2014) The dynamic role of genetics on cortical patterning during childhood and adolescence. Proc Natl Acad Sci U S A 111:6774-6779.

Schnack HG, van Haren NE, Brouwer RM, Evans A, Durston S, Boomsma DI, Kahn RS, Hulshoff Pol HE (2015) Changes in thickness and surface area of the human cortex and their relationship with intelligence. Cereb Cortex 25:1608-1617.

Sled JG, Zijdenbos AP, Evans AC (1998) A nonparametric method for automatic correction of intensity nonuniformity in MRI data. IEEE Trans Med Imaging 17:87-97.

Strike LT, Hansell NK, Couvy-Duchesne B, Thompson PM, de Zubicaray GI, 
McMahon KL, Wright MJ (2019) Genetic complexity of cortical structure: differences in genetic and environmental factors influencing cortical surface area and thickness. Cereb Cortex 29:952-962.

Toro R, Burnod Y (2005) A morphogenetic model for the development of cortical convolutions. Cereb Cortex 15:1900-1913.

Van Essen DC (1997) A tension-based theory of morphogenesis and compact wiring in the central nervous system. Nature 385:313-318.

Walhovd KB, Krogsrud SK, Amlien IK, Bartsch H, Bjørnerud A, DueTønnessen P, Grydeland H, Hagler DJ Jr, Håberg AK, Kremen WS, Ferschmann L, Nyberg L, Panizzon MS, Rohani DA, Skranes J, Storsve AB, Sølsnes AE, Tamnes CK, Thompson WK, Reuter C, et al. (2016) Neurodevelopmental origins of lifespan changes in brain and cognition. Proc Natl Acad Sci U S A 113:9357-9362.
Wallace GL, Schmitt JE, Lenroot R, Viding E, Ordaz S, Rosenthal MA, Molloy EA, Clasen LS, Kendler KS, Neale MC, Giedd JN (2006) A pediatric twin study of brain morphometry. J Child Psychol Psychiatry 47:987-993.

Winkler AM, Kochunov P, Blangero J, Almasy L, Zilles K, Fox PT, Duggirala R, Glahn DC (2010) Cortical thickness or grey matter volume? The importance of selecting the phenotype for imaging genetics studies. Neuroimage 53:1135-1146.

Yoon U, Perusse D, Evans AC (2012) Mapping genetic and environmental influences on cortical surface area of pediatric twins. Neuroscience 220:169-178.

Zijdenbos AP, Forghani R, Evans AC (2002) Automatic "pipeline" analysis of 3-D MRI data for clinical trials: application to multiple sclerosis. IEEE Trans Med Imaging 21:1280-1291. 